\title{
Thermodynamic and Thermo-Econmic Analysis of Preheated and Blended Castor Oil Methyl Ester in a Compression Ignition Engine
}

\author{
Menelik Walle Mekonen ${ }^{1} \&$ Niranjan Sahoo ${ }^{2}$ \\ ${ }^{1}$ Departement of Motor Vehicle Engineering, Defence University College of Engineering, Bishoftu, Ethiopia \\ ${ }^{2}$ Department of Mechanical Engineering, Indian Institute of Technology Guwahati, Guwahati, India \\ Correspondence: Menelik Walle Mekonen, Assistant Professor, Department of Motor Vehicle Engineering, \\ Defence University College of Engineering, Bishoftu, Ethiopia. Tel: 251-114-370-958. E-mail: \\ menelikiitg@gamil.com
}

Received: June 27, 2020

Accepted: December 12, 2020

Online Published: December 15, 2020

doi:10.5539/eer.v10n2p50

URL: https://doi.org/10.5539/eer.v10n2p50

\begin{abstract}
In this paper, energy, exergy, suitability and economic evaluation of a diesel engine running with diesel fuel and five different types of preheated biodiesel blends were evaluated experimentally. The experiments were carried out at varying engine brake mean effective pressures (bmeps). The energy and exergy rate components of the engine were callcualted and compared for each operating conditions and blends of fuel. The fuel properties of the castor oil methyl ester (COME) at different preheating temeperatures have been tested with a consideration of different biodiesel international standards. The test results shows that the fuel properties of COME improve with increase of fuel inlet temeperatures. At $114^{\circ} \mathrm{C}$, kinematic viscosity and density decreased to $\left(5.74 \mathrm{~mm}^{2} / \mathrm{s}\right.$ and 862 $\mathrm{kg} / \mathrm{m}^{3}$ ), whcich is close to diesel fuel, and the brake specific fuel consumption (BSFC) and brake thermal efficiency (BTHE) was improved by $33.1 \%$ and $49.6 \%$ compared to the fuel preheated temeperature of $42^{\circ} \mathrm{C}$. The input fuel energy and exergy rates of blends of fuel were seen to be improved than diesel fuel. The maximum energetic and exergetic efficiency for blended fuels in the test engine at 372 bmep were found in the range of $25-28 \%$ and $23-26 \%$, respectively. The blends of fuel are marginally less sustainable than diesel fuel at every bmeps. The cost analyses show that, all blends of fuel offer quite higher economic cost with respect to diesel fuel. The full economic analysis reveals that only up to $60 \%$ blends of fuel is more affordable as compared to diesel.
\end{abstract}

Keywords: blending, castor oil methyl ester, desel engine, preheating, thermodynamic analysis, thermoeconomic analysis

\section{Introduction}

In many countries, biodiesel is considered as the most valuable alternative energy resources of mineral diesel fuel in a diesel engine due to a rising demands and a gradual depletion of oil reserves of crude oil and serious emission standards (Lin et al., 2006; Naik et al., 2008). Methyl ester oils (biodiesel) derived from different feedstock have similar range of properties as compared to mineral diesel (Balat, 2006). However, they have certain limitations such as, lower calorific value, poor volatility, higher kinematic viscosity and high specific gravity (density) with respect to diesel (Yusuf et al., 2011). Thus, direct application in an existing diesel engine for any blended ratios of biodiesel can cause worse engine performances. At the same time, being an oxygenated fuel, it has potential of improved of $\mathrm{CO}$ and un-burnt hydrocarbons in exhaust emission (Ozsezen \& Canakci, 2011). In this regard, extensive research works done for utilization of biodiesel efficiently in an existing compression ignition engine without any modification (Altın et al., 2001; Khan et al., 2006). The usage of these blended fuel for a substitute of diesel fuel in any compression ignition engine resulted comparable engine performance parameters (BP, BSFC and BTHE) with a meaningful reduction of carbon monoxide (CO), unburned hydrocarbon (UBHC) emissions and smoke (Narayan, 2002; Moon et al., 2010). However, blend ratios greater than $20 \%$ volume biodiesel showed that an extra drop in exhaust emissions (CO and HC), but they have worser engine performance parameters in terms of BSFC and BTHE (Mohan et al., 2014). In order to overcome the existing challenges of biodiesel and used for any blend ratios greater than $20 \%$ biodiesel to neat biodiesel (100\% volume) in an existing compression ignition engine, it is better to optimize the fuel properties biodiesel by preheating process. Preheating is simple, less economical and efficient technique for optimizing the 
performance of biodiesel by reducing the viscosity and density level to the ranges of international biodiesel standards (ASTM D6751 and EN14214). Thereby, it maximizes the combustion and overall engine efficiency that arises from a poor fuel droplet formation and atomization (Aksoy et al., 2009; Venkanna \& Venkataramana, 2013). It can also solve for failures in engine and fuel system components because of carbon deposit, clogging and choking. Hence, a modifications of fuel properties of biodiesel using preheating technique helps to utilize the biodiesel in different levels of blend ratios (20,40,60,80 and 100\% volume) in the existing compression ignition engines without any engine modification and offers a comparable engine performance parameters and less harmful exhaust emissions related to a diesel fuel. The analysis of preheated biodiesel blended fuel run with many aspects plays important role to investigate their sustainability.

In the present study, two important thermodynamics laws are applied to examine the energy potential (both quality and quantity) in a compression ignition engine using pure mineral diesel fuel and five preheated blends of fuel. In compression ignition engines, it is desirable to convert fuel input energy into engine performance at the highest rate, but complete conversion of all the fuel input energy into useful work is not possible (Cengel \& Boles, 2007; Tat, 2011). For this purpose, the laws of thermodynamics (first and second) are generally used for analyzing the engine. The first law is about energy analysis, which can provide information about fuel inlet energy converted into different energy rates (useful shaft work, cooling water, exhaust gas, and uncounted loss). In order to access a most efficient performance of fuels in terms of engine performance, second law analysis (exergy) has to be employed to know the quality of energy (Sorathia \& Yadav, 2012). Exergy analysis is used to realize the actual efficiencies of engine by determining different exergy losses and locating where they occur (da Costa et al., 2012; López et al., 2014). A complete thermodynamics analysis of engine helps to acquire a most convincing picture of engine behavior fueled at different test fuels. These analyses help economic situation, to evaluate the performance of different test fuels for direct application in a compression ignition engine. In this regards, thermo-economic analysis has been carried out for in this study. There are few studies on energy, exergy and economic analysis of compression ignition engines using biodiesel blends. The thermodynamic analysis in a compression ignition engine run with pure diesel fuel and soybean oil methyl ester and high-oleic soybean oil methyl ester have been reported (Meisami et al., 2018). The energetic and exergetic efficiencies were $40.5 \%$ and $37.8 \%$, respectively, for two biodiesel fuels (Caliskan et al., 2010). The first and second law thermodynamics analysis in a diesel engine used with diesel fuel and palm oil methyl ester is studied (Misra et al., 2013). They found that the exergetic efficiency lower than energetic efficiency but follow similar trends. The thermodynamic and economic analysis of a diesel engine running with blends castor oil methyl ester with diesel fuel (Meisami \& Ajam, 2015). They found that $15 \%$ castor oil methyl ester blend with diesel fuel was an optimum compared to other blends of fuel and offered a comparable engine performance parameters related to a diesel fuel. The thermodynamic and economic analysis of a diesel engine using diesel fuel and different blends of biodiesel is also reported (Caliskan \& Mori, 2017). They found that, BSFC increased with increasing percentage fractions of biodiesel in blend ratios and inversely proportional to the lower heating values (LHVs) of the blends of fuel. Increase of the blend ratios of biodiesel is inversely proportional to the fuel input energy and exergy rates of the engine due to LHVs of biodiesel. However, the engine efficiency was found maximum for BDF100 fuel. The entropy generation for all test fuels increased with increasing engine loads. The economic parameters increased with increasing engine load, and was found maximum for BDF100 whereas lower for diesel fuel.

In this paper, the thermo-economic analysis for different test fuels used in a VCR diesel engine is attempted based on first and second law of thermodynamics by considering control volume analysis as shown in Figure 1. The experiments were conducted with a diesel fuel (100D) for baseline data for comparison and various blends of preheated COME (biodiesel) with diesel by volume (20PBD, 40PBD, 60PBD, 80PBD and 100PBD) with varying engine bmeps (41.6 kPa, $206.2 \mathrm{kPa}$ and $372 \mathrm{kPa}$ ) at constant $1500 \mathrm{rpm}$ engine speed. The thermo-economic study involves comparison of energy and exergy efficiency, entropy generation, sustainability and economic analysis for tested fuel samples based on the data obtained from the experiments.

\section{Experimental Setups and Procedures Method}

The setup contains a single cylinder four stroke, direct injection (DI), compression ignition (CI) engine, water-cooled engine (Kirloskar Make: $3.5 \mathrm{~kW}, 1500 \mathrm{rpm}$ ). The engine is operated at compression ratio of 17.5 with fuel injection pressure and injection timing of 200 bar and $23^{\circ}$ BTDC, respectively. The setup is equipped with a biodiesel preheater and a two fuel storage tanks for COME and diesel along with necessary fuel lines and fuel blend metered glass burette (Figure 1). The COME is preheated using an engine waste heat exhaust gasses and its supply to the preheating device is controlled by a manual flow control gate valves of "gv1 and gv2" as shown in Figure 1. The engine is coupled by water-cooled eddy current dynamometer for loading that can be varied manually. The bmeps were obtained from different loads set in the engine. In this study, first neat COME 
was preheated at different fuel inlet temperature in the range of $42^{\circ} \mathrm{C}-138^{\circ} \mathrm{C}$ with increment of $12^{\circ} \mathrm{C}$ at full load (413.82 $\mathrm{kPa}$ bmep) condition. Then important test data were recorded to study the effect of preheating COME on the performance parameter analysis of the engine. Then, the effect of preheating on the fuel properties of COME were studied offline by considering all the temperatures used in the initial experimentation. While measuring the kinematic viscosity and density of COME Redwood viscometer and hydrometer were used. The testing was done with appropriate standards "America society of testing material (ASTM D6751) and European (EN14214)" wherever, applicable. Subsequently, the optimum fuel preheating temperature is identified, which drops the values of the two fuel properties of COME to the ranges of biodiesel standards. At this optimum fuel-preheat temperature, the important blends of samples were prepared on a volumetric basis measured by graduated glass burette for measuring blend fuel property (i.e. kinematic viscosity and density). Later, major experimental tests were carried out to investigate the influence of blends of fuel on thermodynamics and economic analysis of CI engine, with COME preheated at constant fuel inlet temperature $\left(114^{\circ} \mathrm{C}\right)$ before blending with diesel. All the measurements were taken after the steady state condition was reached. The fuel and air consumptions (F1 and F2) for blends of fuel were measured and recorded at every bmeps. The temperatures (T1-T6 as shown in Figure 1) were measured using thermocouples. Using the measured data, the different rates of energy and exergy, energetic and energetic efficiency, entropy generation, and sustainability index were calculated and analyzed for economic analysis of the test fuels. While executing each test, the engine was supposed to start first with diesel fuel and then switched to blends of fuel after 20 min when operating parameters are stabilized. At each test, the required data were recorded in five minutes after the engine was set on the desired conditions. After finishing each test, the engine was switched to run with neat diesel (100D) for about 25 minutes in order to flush out the biodiesel from the fuel line or combustion chamber. All the important fuel properties of neat diesel fuel (100D), unheated COME, and various blends of fuel mentioned in Table 1.

Table 1. Important properties of various blend fuels calculated based on ASTM D6751 and EN14214 standards

\begin{tabular}{|c|c|c|c|c|c|c|c|}
\hline \multirow[t]{2}{*}{ Fuel property } & \multirow{2}{*}{$\begin{array}{l}\text { Diesel } \\
(100 D)\end{array}$} & \multirow{2}{*}{$\begin{array}{c}\text { Biodiesel } \\
(100 B D)\end{array}$} & \multicolumn{5}{|c|}{ Biodiesel Blend } \\
\hline & & & $20 \mathrm{BD}\left(114^{\circ} \mathrm{C}\right)$ & $40 \mathrm{BD}\left(114^{\circ} \mathrm{C}\right)$ & $60 \mathrm{BD}\left(114^{\circ} \mathrm{C}\right)$ & $80 \mathrm{BD}\left(114^{\circ} \mathrm{C}\right)$ & $100 \mathrm{BD}\left(114^{\circ} \mathrm{C}\right)$ \\
\hline $\begin{array}{l}\text { Kinematic } \\
\text { viscosity }\left(\mathrm{mm}^{2} / \mathrm{s}\right)\end{array}$ & $3.53\left(40^{\circ} \mathrm{C}\right)$ & $21.91\left(40^{\circ} \mathrm{C}\right)$ & 4.23 & 4.72 & 5.08 & 5.41 & 5.74 \\
\hline Density $\left(\mathrm{kg} / \mathrm{m}^{3}\right)$ & $842\left(27^{0} \mathrm{C}\right)$ & $943\left(27^{0} \mathrm{C}\right)$ & 844 & 847 & 853 & 861 & 864 \\
\hline Pour point $\left({ }^{\circ} \mathrm{C}\right)$ & -8 & 8 & -4 & 2 & 4.9 & 9 & 12 \\
\hline Flash point $\left({ }^{\circ} \mathrm{C}\right)$ & 63 & 155 & 68 & 76 & 95 & 119 & 143 \\
\hline $\begin{array}{l}\text { Lower heating } \\
\text { value }(\mathrm{MJ} / \mathrm{kg})\end{array}$ & 44.695 & 37.408 & 43.363 & 42.407 & 41.432 & 40.359 & 39.699 \\
\hline Cetane number & 48 & 52.83 & 51.32 & 51.71 & 52.05 & 52.78 & 53.02 \\
\hline $\begin{array}{l}\text { Molecular } \\
\text { formula }\end{array}$ & $\mathrm{C}_{12} \mathrm{H}_{26}$ [24] & $\mathrm{C}_{12} \mathrm{H}_{26} \mathrm{O}_{3}[26]$ & $\mathrm{C}_{14.32} \mathrm{H}_{26.96} \mathrm{O}_{0.35}$ & $\mathrm{C}_{15.46} \mathrm{H}_{28.3} \mathrm{O}_{0.85}$ & $\mathrm{C}_{16.13} \mathrm{H}_{30.43} \mathrm{O}_{1.32}$ & $\mathrm{C}_{17.28} \mathrm{H}_{32.94} \mathrm{O}_{1.99}$ & $\mathrm{C}_{18} \mathrm{H}_{34} \mathrm{O}_{3}[26]$ \\
\hline$\varepsilon_{\text {fuel }}$ & 1.07129 & - & 1.067582 & 1.069524 & 1.071375 & 1.073514 & 1.076905 \\
\hline
\end{tabular}

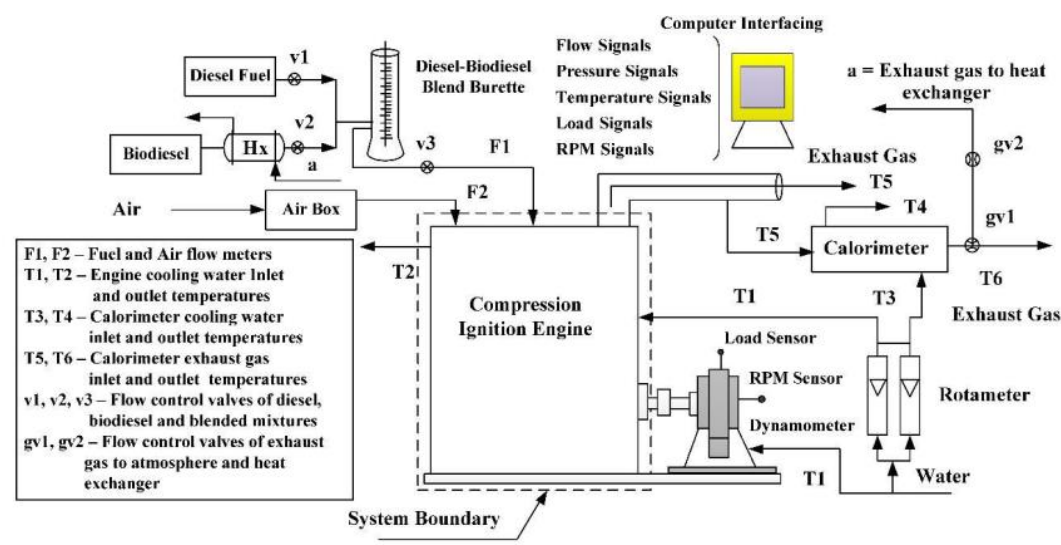

Figure 1. The schematic represnation of the experimental set up 


\section{Thermodynamic Modeling}

In this section, the thermodynamic parameters based on the laws of thermodynamics are obtained by considering the compression ignition (CI) engine as a control volume (Figure 2). The major energy transfer across the boundary in the form of "heat and work" is obtained from the fuel (as input), exhaust gas as outlet stream and shaft power output.

\subsection{First Law of Thermodynamic Analysis}

It deals with the quantitative energy balance in the engine in the form "heat or work". While considering energy input, various test samples of fuels are considered along with their calorific values (Caliskan and Mori 2017). The following assumptions are made; i.e. engine run at steady state, negligible changes in potential and kinetic energy, air and exhaust gas forms ideal gas mixture. The entire system of the engine is modelled as a control volume for which the energy balance of the steady state are given below;

$$
\begin{aligned}
& \sum \dot{H} e_{\text {in }}=\sum \dot{H} e_{(\text {fuel }+ \text { air }) \text { in }}=\sum \dot{H} e_{\text {out }} \\
& \therefore \dot{H} e_{f u e l, i n}=\dot{H} e_{s w}+\dot{H} e_{c w}+\dot{H} e_{e x h}+\dot{H} e_{\text {untd }} \\
& \Rightarrow \dot{H} e_{\text {fuel, in }}(k W)=\dot{m}_{\text {fuel }} \times L H V_{\text {fuel }} \\
& \text { Here, } L H V_{\text {fuel }}=\frac{\left[246.25-0.167 \rho_{\text {fuel }}-12.88 \ln \left(v_{\text {fuel }}\right)\right]}{2} \times 10^{3} \\
& \Rightarrow \dot{H} e_{s w}(k W)=[2 \pi N \times T /(60 \times 1000)] \\
& \Rightarrow \dot{H} e_{c w}(k W)=\dot{m}_{c w} \times C p_{c w}\left(T_{c w, e o}-T_{c w, e i}\right) \\
& \Rightarrow \dot{H} e_{e x h}(k W)=\dot{m}_{e x h} \times \frac{\left[\dot{m}_{c w, c m} \times C p_{c w}\left(T_{c w, c m o}-T_{c w, c m i}\right)\right]}{\dot{m}_{e x h} \times C p_{e x h}\left(T_{e x h, c m i}-T_{e x h, c m o}\right)}\left(T_{e x h, c m i}-T_{0}\right) \\
& \Rightarrow \dot{H} e_{\text {untd }}(k W)=\dot{H} e_{f u e l, i n}-\left(\dot{H} e_{s w}+\dot{H} e_{c w}+\dot{H} e_{e x h}\right)
\end{aligned}
$$

Energetic efficiency ( $\eta_{\text {energ }}$ ) is the ratio of effective shaft work to fuel input energy rate. It is calculated as follow (Caliskan \& Mori, 2017):

$$
\eta_{\text {energ }}(\%)=\left(\dot{H} e_{s w} / \dot{H} e_{\text {fuel, in }}\right) \times 100
$$

Where, $\sum \dot{H} e_{i n}, \sum \dot{H} e_{o u}, \dot{H} e_{f u l l, i n}, \dot{H} e_{s w}, \dot{H} e_{c w}, \dot{H} e_{e x h}, \dot{H} e_{u n t d}$ is the total energy rate input, total energy rate output, the energy rate of input fuel, useful shaft work, cooling water, exhaust gas, and uncounted energy loss, respectively. Other parameters; $\dot{m}_{f u e l}, \dot{m}_{c w}, \dot{m}_{e x h}, C p_{c w}, C p_{e x h}, L H V_{f u e l}, \rho_{f u e l}, v_{f u e l}, N, T$ are mass flow rate of fuel, mass flow cooling water, mass flow exhaust gas, specific heat of water, specific heat of exhaust gas, lo wer heating value of fuel, density of fuel, kinematic viscosity of fuel, engine speed (rpm) and engine $\mathrm{t}$ orque (Nm), respectively. And, $T_{c w, e o}, T_{c w, e i}, T_{c w, c m o}, T_{c w, c m i}, T_{e x h, c m i}, T_{e x h, c m o}, T_{0}$ are engine cooling water outlet, engine cooling water inlet, calorimeter cooling water outlet, calorimeter cooling water inlet, calorimeter exhaust gasoutlet, calorimeter exhaust gas inlet, ambient temperature, respectively.

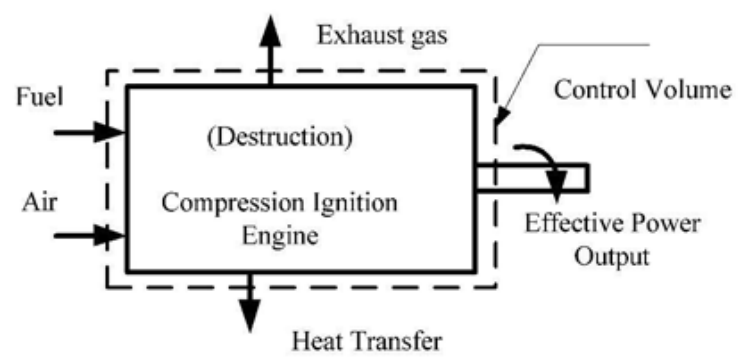

Figure 2. The control volume of a CI engine 


\subsection{Second Law of Thermodynamic Analysis}

The analysis is based on first and second laws of thermodynamics. The aim of this analysis to identify the exergetic efficiency, the amount of losses and destruction of engine run with blends of fuel. The exergy balance for steady-state control volume (Figure 2) is given as follows (Debnath et al., 2013; Caliskan \& Mori, 2017):

$$
\begin{aligned}
& \sum E x_{\text {in }}=\sum \dot{E} x_{\text {out }}+\sum \dot{E} x_{\text {destr }} \\
& \therefore \dot{E} x_{\text {fuel }, \text { in }}=\dot{H} e_{s w}+\dot{E} x_{c w}+\dot{E} x_{e x h}+\dot{E} x_{\text {destr }} \\
& \Rightarrow \dot{E} x_{\text {fuel, in }}(k W)=\dot{m}_{\text {fuel }} \times L H V_{\text {fuel }} \times \varepsilon_{\text {fuel }} \\
& \text { Here, Chemical Exergy factor of fuel }\left(\varepsilon_{\text {fuel }}\right) \text {, } \\
& \varepsilon_{\text {fuel }}=1.0401+0.1728(h / c)+0.0432(\mathrm{o} / \mathrm{c})+0.2169(\mathrm{~s} / \mathrm{c})[1-2.0628(\mathrm{~h} / \mathrm{c})] \\
& \Rightarrow \dot{E} x_{s w}(k W)=\dot{H} e_{s w}(k W) \\
& \Rightarrow \dot{E} x_{c w}(k W)=\left\{\dot{H} e_{c w}(k W)-\left[\left(\dot{m}_{c w} / 3600\right) \times C p_{c w} \times T_{0} \ln \left(T_{c w, e o} / T_{c w, e i}\right)\right]\right\} \\
& \Rightarrow \dot{E} x_{e x h}(k W)=\dot{H} e_{e x h}(k W)+\left(\dot{m}_{c w} / 3600\right) \times C p_{c w} \times T_{0}\left[C p_{e x h} \ln \left(T_{0} / T_{e x h, c m i}\right)-R_{e x h} \ln \left(P_{0} / P_{e x h, c m i}\right)\right] \\
& \text { Here, } R_{e x h}=R_{u} / M W_{e x h} ; \quad P_{e x h}=\rho_{e x h} R_{e x h} T_{e x h, c m i} \\
& \Rightarrow \dot{E} x_{\text {destr }}(k W)=\dot{E} x_{f u e l, \text { in }}-\left(\dot{E} x_{s w}+\dot{E} x_{c w}+\dot{E} x_{e x h}\right)
\end{aligned}
$$

The exergetic efficiency $\left(\eta_{\text {exerg }}\right)$ and entropy generation rate $\left(S_{\text {gen }}\right)$, can be calculated (Caliskan \& Mori, 2017);

$$
\begin{aligned}
& \eta_{\text {exerg }}(\%)=\left(\dot{E} x_{s w} / \dot{E} x_{\text {fuel, in }}\right) \times 100 \\
& S_{g e n}(k W / K)=\left(\dot{E} x_{\text {destr }} / T_{0}\right)
\end{aligned}
$$

Where, $\sum \dot{E} x_{i n}, \sum \dot{E} x_{o u}, \dot{E} x_{f u e l, i n}, \dot{E} x_{s w}, \dot{E} x_{c w}, \dot{E} x_{e x h}, \dot{E} x_{d e s t r}$ is the total exergy rate input, total exergy rateoutput, the exergy rate of input fuel, useful shaft work, cooling water, exhaust gas, and destruction, repectively. Other parameters $P_{e x h}, P_{o}, R_{u}, M W_{e x h}, \rho_{e x h}$ are density of exhaust gas, ambient pressure (1 bar), universal gasconstant $(8.314 \mathrm{Kj} / \mathrm{kmol} . \mathrm{K})$, molecular weight exhaust gas $(29 \mathrm{~g} / \mathrm{mol}$.), respectively, and h, c, o and $\mathrm{s}$ is the mass ratios of hydrogen, carbon, oxygen and sulphur of diesel fuel and different blends of fuel.

\subsection{Sustinability Analysis}

It is required for efficient and effective use of fuel resources, and related with sustainability index (SI) method. The sustainability index method is a suitable technique to find sustainability of the system (Caliskan \& Mori, 2017). It is expressed as function of exergy efficiency.

$$
S I=1 /\left(1-\eta_{\text {exerg }}\right)
$$

\subsection{Thermo-Economic Analysis}

It is a method of exergy based economic analysis in which costs are better distributed among outputs. In this analysis the relation between different exergy streams of inlet fuel, useful work, cooling water, exhaust gases and destruction, and capital investments. The exergy and economic balance of steady state control volume of compression ignition engine shown in Figure 2 can be given in equation (7), as follows (Meisami et al., 2018):

$$
\begin{aligned}
& \dot{E} x_{h t}+\sum \dot{m}_{i} e_{i}=\dot{E} x_{s w}+\sum \dot{m}_{e} e_{e}+\dot{E} x_{d e s t r} \\
& \sum \dot{C}_{e}+\dot{C}_{s w}=\dot{C}_{h t}+\sum \dot{C}_{i}+\dot{Z} \\
& \Rightarrow \sum \dot{m}_{i} e_{i}=\dot{E} x_{f u e l}+\dot{E} x_{\text {air }} \\
& \Rightarrow \sum \dot{m}_{e} e_{e}=\dot{E} x_{e x h} \\
& \Rightarrow \dot{C}_{i}=c_{i n} \dot{E} x_{i n}=c_{f u e l} \dot{E} x_{f u e l} \\
& \Rightarrow \dot{C}_{e}=c_{e x i t} \dot{E} x_{e x i t}=c_{e x h} \dot{E} x_{e x h}
\end{aligned}
$$


In the present study, we assumed that the cost rate associated with the inlet air induced into the engine is neglected, hence we can rewrite equation (7) in to equation (8), and the economic balance for the engine can be written as follows:

$$
\dot{C}_{e h x}+\dot{C}_{s w}=\dot{C}_{h t}+\dot{C}_{f u e l}+\dot{Z}
$$

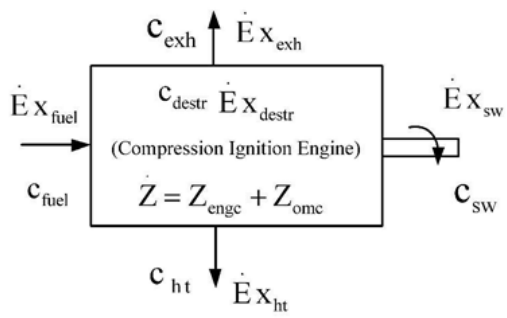

Figure 3. The exergy and cost rate stream of the CI engine

In this study, a cost balance applied to a component shown in Figure 3, was expressed as the equal sum between the sum of cost rates associated with all exiting exergy streams $\left(C_{s w}\right)$ and the sum of cost rates of all entering exergy streams $\left(C_{f u e l}\right)$ plus the appropriate cost rates due to the capital investment of the compression ignition engine $\left(Z_{\text {engc }}\right)$, and operating and maintenance expense $\left(Z_{\text {omc }}\right)$. The cost rate associated with different blends of fuel can be defined as follows (Meisami et al., 2018):

$$
\begin{aligned}
& \dot{C}_{f u e l}=c_{f u e l} \dot{E} x_{f u e l} \\
& \dot{C}_{s w}=c_{s w} \dot{E} x_{s w} \\
& \dot{C}_{e h x}=c_{e x h} \dot{E} x_{e x h} \\
& \dot{C}_{h t}=c_{h t} \dot{E} x_{h t} \\
& \dot{C}_{d e s t r}=c_{d e s t r} \dot{E} x_{d e s t r} \\
& \dot{Z}=Z_{\text {engc }}+Z_{\text {omc }}
\end{aligned}
$$

Thus, substitute equation (9) in to equation (8), the cost rate balance for the engine equation (10) can be rewritten as follows (Meisami et al., 2018):

$$
c_{\text {exh }} \dot{E} x_{\text {exh }}+c_{s w} \dot{E} x_{s w}=c_{h t} \dot{E} x_{h t}+c_{\text {fuel }} \dot{E} x_{f u e l}+c_{\text {destr }} \dot{E} x_{\text {destr }}+Z_{\text {engc }}+Z_{\text {omc }}
$$

However, in this analysis we considered that the cost rate associated with the inlet air induced into the engine, exhaust gases loss and heat loss due to cooling water were neglected (Meisami et al., 2018). Thus, the cost rates associated with different blends of fuel of equation (11) can be written as follows;

$$
\begin{gathered}
c_{s w} \dot{E} x_{s w}=c_{f u e l} \dot{E} x_{f u e l}+c_{\text {destr }} \dot{E} x_{\text {destr }}+Z_{\text {engc }}+Z_{\text {omc }} \\
\text { The cost of heat loss and destruction can be rewrite; } c_{f u e l}=c_{\text {loss }}=c_{\text {destr }} \\
\Rightarrow c_{s w} \dot{E} x_{\text {sw }}=c_{f u e l} \dot{E} x_{f u e l}+c_{f u e l} \dot{E} x_{\text {destr }}+Z_{\text {engc }}+Z_{\text {omc }} \\
\text { Thus, cost per useful power exergy' } c_{\text {sw }}{ }^{\prime} \text { and destruction of exergy' } \\
c_{\text {sw }}(\$ / M J)=\frac{\left(c_{\text {fuel }} \dot{E} x_{f u e l}+c_{f u e l} \dot{E} x_{\text {destr }}+Z_{\text {engc }}+Z_{\text {omc }}\right)}{\dot{E} x_{\text {sw }}} \\
c_{\text {destr }}(\$ / M J)=\frac{\left(c_{\text {sw }} \dot{E} x_{f u e l}+c_{f u e l} \dot{E} x_{f u e l}+Z_{\text {engc }}+Z_{\text {omc }}\right)}{\dot{E} x_{\text {destr }}}
\end{gathered}
$$

Where, $\dot{C}_{i}, \dot{C}_{e}, \dot{C}_{f u e l}, \dot{C}_{s w}, \dot{C}_{h t}, \dot{C}_{\text {exh }}, \dot{C}_{\text {destr }}, Z_{\text {engc }}, Z_{\text {omc }}$ are the cost rate of inlet, cost rate of outlet streams, the cost rate associated with the inlet exergy fuel, useful exergy, heat loss, exhaust gas, and destruction exergy, the appropriate cost rates due to the capital investment of the compression ignition engine, and operating and maintenance expense $\left(Z_{\text {omc }}\right)$, respectively in $\$ / \mathrm{hr}$. and $c_{f u e l}, c_{s w}, c_{h t}, c_{e x h}, c_{\text {destr }}$, are cost per unit exergies of inlet fuel, useful shaft power, heat transfer (loss), exhaust gas, and destruction, respectively. 
Table 2. The fuel cost running fuel and exergy rate associated with test fuels

\begin{tabular}{ccccccc}
\hline Test fuel & Cost per liter of fuel (USD, \$/Lt.) & $E_{X_{\text {fuel }}}(\mathrm{MJ} / \mathrm{hr})$. & $\dot{E x}_{\text {sw }}(\mathrm{MJ} / \mathrm{hr})$. & $\mathrm{Ex}_{\text {destr }}(\mathrm{MJ} / \mathrm{hr})$. & $Z_{\text {engc }}(\$ / \mathrm{hr})$ & $Z_{\text {omc }}(\$ / \mathrm{hr})$ \\
\hline 100D & 1.029757 & 40.652 & 11.108 & 27.469 & 0.03126 & 0.02726 \\
20PBD & 1.528583 & 42.510 & 11.144 & 29.202 & 0.03126 & 0.02726 \\
40PBD & 2.027408 & 43.494 & 11.031 & 30.327 & 0.03126 & 0.02726 \\
60PBD & 2.526233 & 44.561 & 11.012 & 31.388 & 0.03126 & 0.02726 \\
80PBD & 3.025059 & 45.201 & 10.946 & 32.052 & 0.03126 & 0.02726 \\
100PBD & 3.523884 & 45.929 & 10.887 & 32.815 & 0.03126 & 0.02726 \\
\hline
\end{tabular}

Note. INR: Indian Rupee (Indian currency). In India for Friday, 16 Feb, 2018, $1 \$$ is equal to 63.85 INR.

The purchased cost of the neat COME (100BD) and diesel fuel (100D) based on the India fuel market price on Friday, 16 Feb, 2018 are INR 225 and 65.75 per liter of COME and diesel fuel respectively. While, the costs of different blends of fuel can be computing with rough estimation of price biodiesel and diesel fuel separately based on their percentage ratios of each blended fuel. The Indian market price per liter of diesel (100D) and different blends fuel (20PBD, 40PBD, 60PBD, 80PBD and 100PBD) has shown in the Table 2. It is clear seen that, engine running with different blends of biodiesel are costly as compared to diesel fuel (100D). Though, the small scale production of castor oil methyl ester (biodiesel) with the trans-esterification reaction caused to have a higher cost compared to mineral diesel fuel. While, in India diesel fuel has the lower price, this is due to the Indian government grants a huge subsidy on diesel fuel. It has been recommended that a thorough study has required for the feasibility analysis of different blends of biodiesel by comparing it production cost with market price of diesel fuel.

To investigate and compare the exergy costs between different blends of fuel with neat diesel fuel, the required data of cost per generated useful exergy, cost per destroyed exergy and fuel exergy associated with each of test fuels must be determined (as shown in Table 2). The purchased initial cost of Krloskar single cylinder variable compression ratio (VCR) direct injection (DI) compression ignition engine (made in India) in USA dollars was 1188.671875 \$, the expected lifespan of engine is 16-year. The annual operating hours of the engine, this is considered to be $2376 \mathrm{hrs} /$ year ( $8 \mathrm{hrs}$ per day for 297 working days). Thus the total investment cost of the engine $\left(\mathrm{Z}_{\text {engc }}\right)$ to be $0.03126 \$ / \mathrm{hrs}$. While, the annual operating and maintenance hours of a diesel engine for 68 days are 612 hrs (68 days x 9hrs/day) with a onetime operating and maintenance cost of 8.34375 . Hence the total operating and maintenance cost $\left(\mathrm{Z}_{\mathrm{omc}}\right)$ to be $0.02726 \$ / \mathrm{hrs}$.

\section{Results and Discussion}

\subsection{Improvement of Fuel Propeties of Castor Oil Methyl Ester}

Here, experiments were conducted in the engine with neat castor oil methyl ester (COME) under preheated conditions of nine different fuel inlet temperatures $\left(42,54,66,78,90,102,114,126\right.$ and $\left.138^{\circ} \mathrm{C}\right)$. All the tests are undertaken at constant full engine load (413.82 kPa of bmep) and engine speed of $1500 \mathrm{rpm}$. First engine tested with diesel fuel for warmup and bring waste exhaust gas at a minimum preheating fuel temperature. Then, complete experimentation was conducted using a different blends of fuel at standard operating condition (compression ratio - CR 17.5, fuel injection pressure - IP $200 \mathrm{bar}$, fuel injection timing - IT $23^{\circ} \mathrm{BTDC}$ : BTDC before top dead center) at bmep $413.82 \mathrm{kPa}$ operating condition.

The experimental fuel requires it to meet a set of specifications which are defined in ASTM D 6751 and EN 14214 standards. The fuel properties of COME: density, kinematic viscosity, flashpoint, lower heating values and cetane number (shown in Table 1) were, $943 \mathrm{~kg} / \mathrm{m}^{3}, 21.91 \mathrm{~mm}^{2} / \mathrm{s}, 155{ }^{\circ} \mathrm{C}, 37.41 \mathrm{MJ} / \mathrm{kg}$ and 52.83 , respectively. The values indicate that most of the properties are beyond the limits of both standards and requires a treatment for optimizing the performance of COME usage as a diesel fuel in the engine for any blend ratios. The lower heating values of COME is $16.3 \%$ lower than diesel, while density of COME is $11.99 \%$ higher and the kinematic viscosity six times higher than diesel fuel. Thus using neat COME directly in a compression ignition engine influence adversely on performance and emission parameters. Hence, the fuel properties of COME (high oil viscosity and density) has to be decreased to an acceptable ranges of biodiesel standards declared in (ASTM-D6751 and EN 14214) to have a better fuel atomization, vaporizations rate and mixing process of injected biodiesel in a combustion chamber (Kegl et al., 2013).

In this study, the effect of preheating on kinematic viscosity and density of COME were investigated at full engine load or $413.82 \mathrm{kPa}$ engine bmep operating condition. The test results are illustrated in Figure 4(a-b). Noticeably, the kinematic viscosity and density of COME gradually decrease with increasing fuel preheating 
temperatures (Karabektas et al., 2008, Rambabu et al., 2013). It is seen that, when preheating temperature of COME is increased to $138^{\circ} \mathrm{C}$, the kinematic viscosity and density values was decreased and closely match with the values as per the ASTM-D6751 and EN 14214 biodiesel standards discussed in literature (Knothe, 2006). It is seen in Fig.4 $(\mathrm{a}-\mathrm{b})$ that, at $114^{\circ} \mathrm{C}$ fuel preheating inlet temperature the kinematic viscosity and density value of COME was decreased to $5.74 \mathrm{~mm}^{2} / \mathrm{s}$ and $862 \mathrm{~kg} / \mathrm{m}^{3}$, respectively and close to diesel fuel $\left(3.53 \mathrm{~mm}^{2} / \mathrm{s}\right.$ at $40^{\circ} \mathrm{C}$ and $842 \mathrm{~kg} / \mathrm{m}^{3}$ at $27^{\circ} \mathrm{C}$ as shown in Table 1$)$. Increasing to $126^{\circ} \mathrm{C}$ and $138^{\circ} \mathrm{C}$ fuel preheating temperature the value of the fuel properties of COME was shown decreased further, however excessive heating of biodiesel caused to worsen engine performance parameters (as seen in Figure 5) due to a sever leakage of biodiesel from fuel injection pump and injector nozzle. Excessive heating of biodiesel may create "vapor lock" in the fuel line and has a negative consequence with respect to lubricity problems due to severe fuel leakage. Because of this fact, there is intermittent fuel supply and engine may stop suddenly. For this reason, the optimum fuel preheating temperature of COME $114^{\circ} \mathrm{C}$ is chosen as for which the minimum brake specific fuel consumption (BSFC) and maximum brake thermal efficiency (BTHE) diesel engine were obtained $0.33878 \mathrm{~kg} / \mathrm{kW} . \mathrm{hr}$ and $26.96 \%$, respectively (Figure 5). The BSFC obtained at $126^{\circ} \mathrm{C}$ and $138^{\circ} \mathrm{C}$ was on averages of $0.63 \%$ and $1.17 \%$, respectively higher than $\mathrm{BSFC}\left(114^{\circ} \mathrm{C}\right)$, whereas the $\mathrm{BTHE}$ was on averages of $1.41 \%$ and $6.67 \%$ lower than BTHE $\left(114^{\circ} \mathrm{C}\right)$ operating condition.
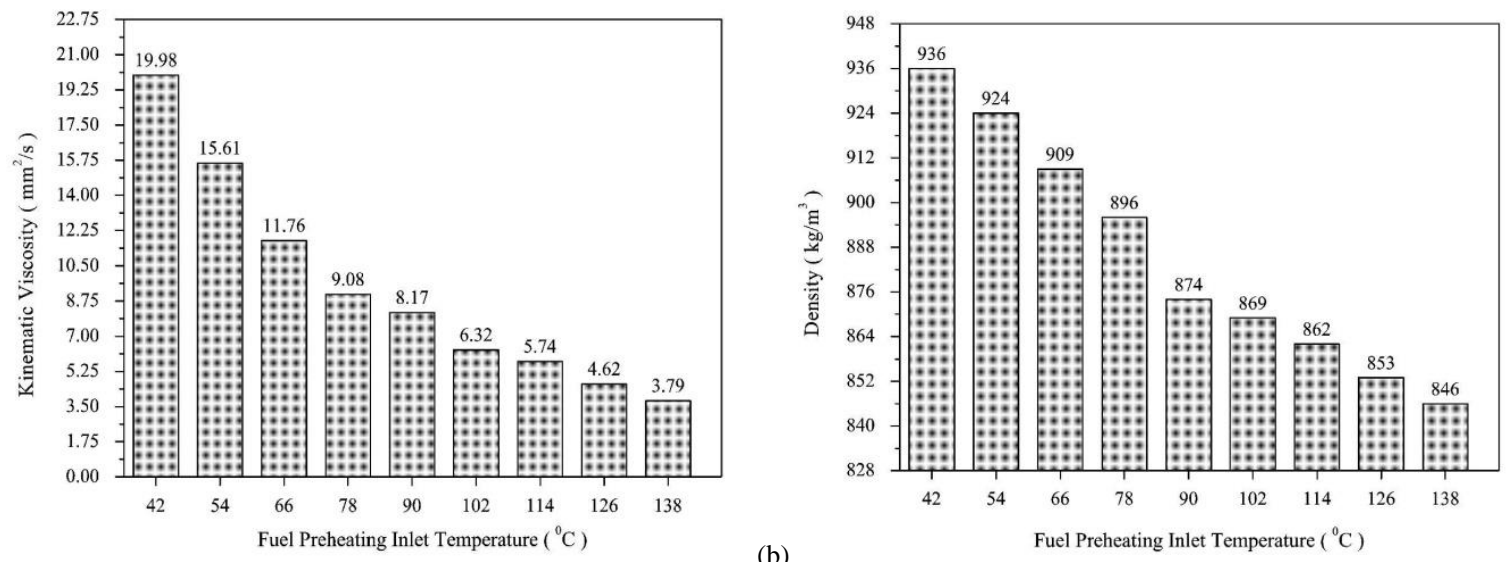

Figure 4. Fuel property of COME with preheating temperature: (a) Kinematic viscosity, and (b) Density

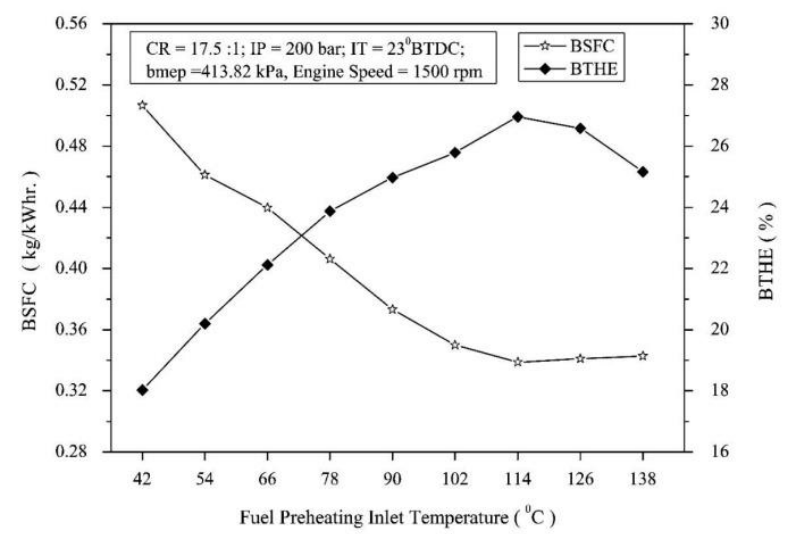

Figure 5. Engine BSFC and BTHE with fuel preheating inlet temperature of COME (biodiesel)

\subsection{Effect of Preheating and Blend Ratios on LHVs and BSFCs}

The LHV of a fuel, which is defined as the amount heat released by combusting a specified quantity a fuel in an engine after the latent heat of vaporization. It is the energy input in the engine. The LHVs of all fuels are measured using bomb calorimeter. The biodiesel has lower LHV compared to neat diesel fuel; however preheating marginally improved the LHVs of neat COME from 37.408 to $39.699 \mathrm{MJ} / \mathrm{kg}$ (Table 1). In addition to the preheating COME, blending with diesel fuel benefit to boost the LHVs of different blends of fuel. It is seen 
in Table 1 that, the highest LHV is attained for 100D, while the least was occurred for the 100PBD. Hence, the LHVs of blends of fuel are explained from least to highest: 100PBD < 80PBD < 60PBD < 40PBD < 20PBD < 100D. The result implies that increasing the percentage of fraction of biodiesel in the blend ratio decrease the LHVs of blends of fuel.

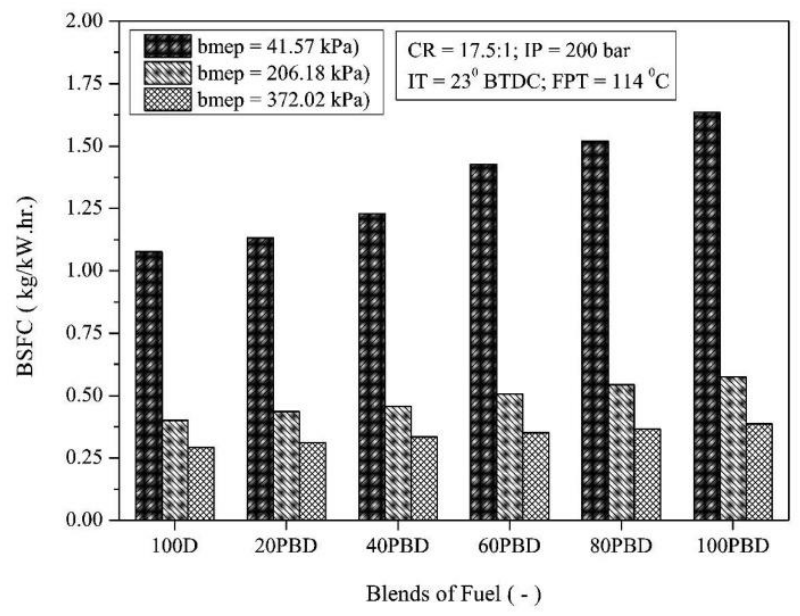

Figure 6. The variations of brake specific fuel consumptions with blends of fuel

The variation brake specific fuel consumption (BSFC) for the all blends of fuel with varying bmeps is displayed in Figure 6(b). The BSFC of 100PBD fuel was found maximum for varied engine bmeps. This is due to the relatively high kinematic viscosity and poor mixture formation of 100PBD even after preheated. Preheating $\mathrm{COME}$ at $114^{\circ} \mathrm{C}$ and blending with diesel fuel for different ratios cause to further improved the fuel property of COME (viscosity, density and heating values), this enhances better fuel injection and thereby better fuel atomization. It is seen in Figure 6, the BSFCs of the blends of fuel are in order from minimum to maximum:

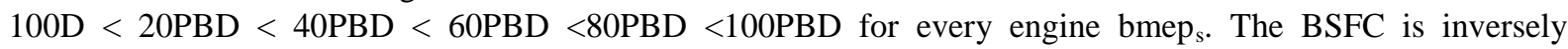
proportional to the percentage fractions of biodiesel. The significant reduction on BSFC values are seen up to $206.18 \mathrm{kPa}$ engine bmep, beyond this there is a slight variation among all test fuels. The reason is that, at lower bmep, the amount fuel injected into engine combustion chamber is higher whereas the amount of intake air in engine cylinder is lower; this leads a richer mixture ratio and incomplete combustion. The trend of BSFC is seen to decrease with increase bmep. This is mainly due to the improvement of combustion efficiency of injected fuel with increasing a suction of more intake air into the engine cylinder, which is can produce the same brake power compared 100D.

\subsection{Thermodynamic Analyses}

In this study, diesel fuel (100D) and five preheated blends of fuel are used in the compression ignition engine at varying engine bmeps $(41.57,206.18$ and $372.02 \mathrm{kPa})$, respectively. The air and fuel consumption of engine, engine and calorimeter cooling water inlet and outlet temperatures and exhaust gas temperatures are measured and recorded during each test to evaluate the engine energy and exergy analysis, sustainability, and thermos-economic analysis of engine.

\subsubsection{Energy Analyses}

The distributions of energy rates of compression ignition engine fueled with different blends of fuel at varied engine bmeps are calculated and tabulated in Table 3. It is seen that, all energy rates except the energy rate of useful shaft work are directly proportional to the blends of fuels. At $372.02 \mathrm{kPa}$ of bmep, the useful shaft work slightly decreases (as much as 1.99\%) when using 100PBD as fuel compared to 100D. This is because of the lower LHV and higher kinematic viscosity of biodiesel. It is seen in Figure 7 that, the amount of input fuel energy rates increased with increasing the percentage fractions of biodiesel in blend ratios. It is mostly depending on the mass flow rate fuel for a given time interval. At high levels of biodiesel blends, engine consumed more fuel, this due to the increasing the percentage fractions of biodiesel in blend ratios the quality of the fuel getting decreased resulting engine consumed high volume of fuel to produced similar power output comparing with low levels of blended fuel or diesel fuel for fixed running time. Thus, the input fuel energy rate from maximum to minimum are as follows 100PBD > 80PBD > 60PBD > 40PBD > 20PBD > 100D. Since, the BSFC directly proportional to the blends of fuel (Figure 6b), which results that input fuel energy rate is 
maximum at high level of biodiesel blends. Increasing the percentage fraction of biodiesel in the blend ratios causes a drop generating useful shaft work converted from the input energy rate. Because of the inferior quality fuel atomization and mixing rate which results more in energy loss, due to high viscosity and density of high levels blends of fuel. However, exhaust gases and uncounted energy loss were found higher. This means more exhaust gases energy or energy loss in the engine for a high levels blends of fuel. Hence, low blends preheated biodiesel only consider a better option. The fuel energy rates take away by cooling water heat transfer for all blends of fuel almost identical with varying engine bmeps.

Furthermore, the compression ignition engine has a better energetic efficiency when operated at low levels blend ratios for every engine bmeps. Energetic efficiency is the measure of how efficiently fuel energy input is converted to useful shaft work in the engine. As can be seen from the Figure 8, more efficient conversion occurs engine with neat diesel fuel (100D) usage and gave a higher energetic efficiency whereas neat preheated biodiesel (100PBD) fuel was found relatively minimum for every engine bmeps. This is due to the lower LHV of the COME. The combined effects preheating and blending COME with diesel fuel is helped to increase the LHVs of COME, and the values of each test fuels vary with one another depends of the percentages of biodiesel in blend ratios. At $372.02 \mathrm{kPa}$ of bmep, the energetic efficiencies of all blends of fuel change from $25.52 \%$ to $29.12 \%$. The energetic efficiency of the engine considering fuels from lower to higher are: $100 \mathrm{PBD}<80 \mathrm{PBD}<$ $60 \mathrm{PBD}<40 \mathrm{PBD}<20 \mathrm{PBD}<100 \mathrm{D}$.

Table 3. Results of energy rate analysis

\begin{tabular}{|c|c|c|c|c|c|c|}
\hline \multirow{2}{*}{ Fuel } & \multirow{2}{*}{ bmep $(\mathrm{kPa})$} & \multicolumn{5}{|c|}{ Energy rates $(\mathrm{kW})$} \\
\hline & & $\mathrm{H} \mathrm{e}_{\text {fucl }}$ & $\mathrm{He}_{\mathrm{sw}}$ & $\mathrm{He}_{\mathrm{cw}}$ & $\mathrm{He}_{\text {exh }}$ & $\mathrm{He}_{\text {untd }}$ \\
\hline \multirow[t]{3}{*}{$100 \mathrm{D}$} & 41.57 & 5.42 & 0.37 & 0.39 & 0.67 & 3.99 \\
\hline & 206.18 & 7.83 & 1.74 & 0.93 & 1.09 & 4.07 \\
\hline & 372.02 & 10.59 & 3.08 & 2.34 & 1.68 & 3.49 \\
\hline \multirow[t]{3}{*}{ 20PBD } & 41.57 & 5.70 & 0.37 & 0.47 & 0.69 & 4.17 \\
\hline & 206.18 & 8.31 & 1.76 & 1.28 & 1.13 & 4.14 \\
\hline & 372.02 & 11.05 & 3.09 & 2.45 & 1.70 & 3.81 \\
\hline \multirow[t]{3}{*}{ 40PBD } & 41.57 & 5.79 & 0.36 & 0.34 & 0.73 & 4.36 \\
\hline & 206.18 & 8.46 & 1.75 & 0.91 & 1.10 & 4.70 \\
\hline & 372.02 & 11.30 & 3.07 & 2.58 & 1.69 & 3.96 \\
\hline \multirow[t]{3}{*}{ 60PBD } & 41.57 & 6.08 & 0.36 & 0.36 & 0.75 & 4.61 \\
\hline & 206.18 & 8.88 & 1.71 & 1.12 & 1.13 & 4.92 \\
\hline & 372.02 & 11.56 & 3.06 & 2.66 & 1.71 & 4.13 \\
\hline \multirow[t]{3}{*}{ 80PBD } & 41.57 & 6.22 & 0.35 & 0.38 & 0.75 & 4.74 \\
\hline & 206.18 & 9.19 & 1.70 & 1.30 & 1.13 & 5.06 \\
\hline & 372.02 & 11.71 & 3.04 & 2.75 & 1.72 & 4.20 \\
\hline \multirow[t]{3}{*}{ 100PBD } & 41.57 & 6.34 & 0.35 & 0.37 & 0.77 & 4.86 \\
\hline & 206.18 & 9.48 & 1.69 & 1.53 & 1.17 & 5.09 \\
\hline & 372.02 & 11.85 & 3.02 & 3.09 & 1.73 & 4.01 \\
\hline
\end{tabular}

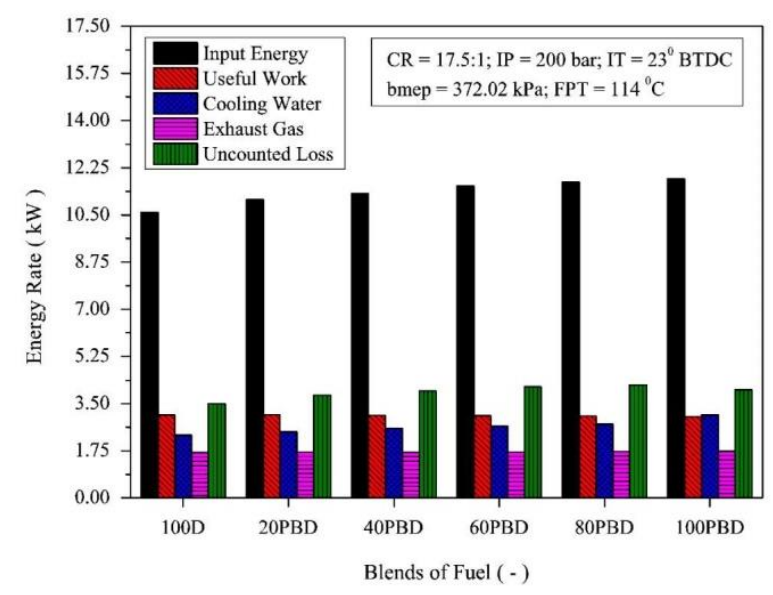

Figure 7. The energy rates of engine for blends of fuels at $372.02 \mathrm{kPa}$ engine bmep 


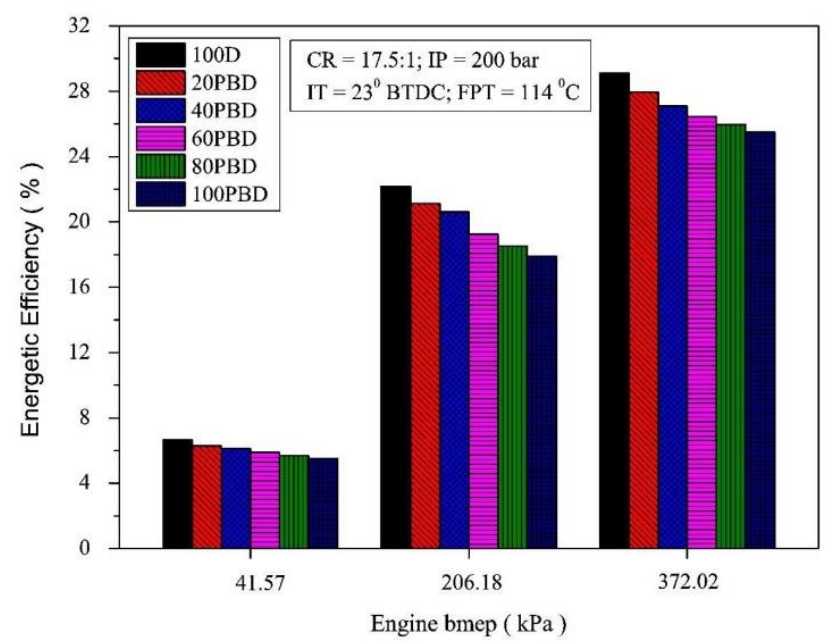

Figure 8. The energetic efficiency of compression ignition engine for various blends of fuel

\subsubsection{Exergy Analysis}

The findings of exergy rates analysis of the compression ignition engine of blends of fuel are included in Table 4 . It signifies the input fuel exergy, exergy of useful work, exergy related with cooling water and exhaust gases, and destroyed exergy of the engine for various blends of fuel operated at varying engine bmeps conditions. It has a same fashion with fuel energy rate since all rates are functions of the mass flow rate and the LHVs of fuel. At $372.02 \mathrm{kPa}$ bmep, it is seen in Figure 9 that the fuel input exergy rates for all blends of fuel are 7.12 to $7.69 \%$ times higher than the fuel input energy rates. The chemical exergy factor, also influences the fuel exergy rate, which make the fuel exergy rate is higher as compared with fuel energy rate. At $372.02 \mathrm{kPa}$ bmep, the input fuel exergy of neat diesel fuel (100D) is $12.44 \%$ lower than that of preheated neat COME (100PBD) due to a lower fuel consumption diesel fuel per unit time. The exergy rates of fuel input, useful shaft work, exhaust gas, destruction are increased with increasing engine bmeps of all blends of fuel. It is also seen Fig. 9 that, all exergy rates except the exergy rate of useful shaft work, directly proportional to the blends of fuels. At $206.18 \mathrm{kPa}$ and $372.02 \mathrm{kPa}$ of bmep, the exergy rate of useful shaft work slightly decreases (as much as $2.43 \%$ and $1.99 \%$ ), respectively when using 100PBD as fuel compared to 100D fuel. The input fuel exergy rate from higher to lower are as follows: $100 \mathrm{PBD}>80 \mathrm{PBD}>60 \mathrm{PBD}>40 \mathrm{PBD}>20 \mathrm{PBD}>100 \mathrm{D}$. The chemical exergy factors and fuel consumption for each fuel play important role on input fuel exergy.

The useful shaft exergy rate remains almost the same with the useful energy rates for all fuels. The exergy rate of useful work for all blends of fuel decreased with increasing percentage fractions of biodiesel in ratio for every bmeps (Table 4). This is because of the lower LHVs of and higher viscosity of biodiesel. This significantly drops the combustion efficiency and increased power loss. For all blends of fuel, the calculation indicates that 23.7$27.2 \%$ of the chemical exergy input is converted into useful shaft work in the engine at $372.02 \mathrm{kPa}$ bmep operation (Figure 9).

Subsequently, the exergy rates of exhaust gas marginally increased with increasing the percentage fractions of biodiesel in blend ratios for every engine bmep (Table 4), because of increased input exergy entering the engine cylinder. The change of exergy rate of exhaust gas loss for blends of fuel is initiated from variances of the exhaust temperatures. The exergy rate of exhaust gas loss for all blend of fuels are higher than diesel fuel (Figure 9). This is because of biodiesel offer maximum exhaust gas temperatures. It is seen in Table 5 that, the exergy rate of cooling water slightly increasing with increasing percentage fraction of biodiesel in blend ratios. At $372.02 \mathrm{kPa}$, the calculation indicates that 13.35 to $13.9 \%$ of the chemical exergy input is lost because of cooling water and exhaust gases respectively for different blends of fuel.

The rate of exergy destruction with blends of fuel for every bmeps, shown that slightly increased with increasing percentage fraction of biodiesel in blend ratios (Figure 10b). The most important source of destruction is irreversibility in the engine combustion processes, heat transfer, friction and mixing. However, the exergy destruction for all tested fuels decrease with an increasing bmeps. This is can be due to a higher excess air coefficient at higher bmep and sufficient time for heat transfer. At $372.02 \mathrm{kPa}$ bmep operation, for all blends of fuel, the calculation indicates that $59.46-62.4 \%$ of the chemical exergy input is destroyed because of irreversibility from the engine. 
Table 4. Results of exergy rate analysis

\begin{tabular}{ccccccc}
\hline \multirow{2}{*}{ Fuel } & bmep $(\mathrm{kPa})$ & \multicolumn{5}{c}{ Exergy rates $(\mathrm{kW})$} \\
\cline { 3 - 7 } & & $E_{X_{\text {fuel }}}$ & $E_{X_{\text {Sw }}}$ & $E_{X_{\text {ew }}}$ & $E_{X_{\text {exh }}}$ & $E_{X_{\text {destr }}}$ \\
\hline \multirow{2}{*}{ 100D } & 41.57 & 5.81 & 0.36 & 0.05 & 0.11 & 5.28 \\
& 206.18 & 8.39 & 1.74 & 0.14 & 0.51 & 6.01 \\
& 372.02 & 11.35 & 3.08 & 0.46 & 1.05 & 6.75 \\
20PBD & 41.57 & 6.08 & 0.36 & 0.05 & 0.13 & 5.54 \\
& 206.18 & 8.87 & 1.75 & 0.21 & 0.53 & 6.38 \\
40PBD & 372.02 & 11.81 & 3.09 & 0.49 & 1.07 & 7.14 \\
& 41.57 & 6.19 & 0.35 & 0.04 & 0.17 & 5.62 \\
60PBD & 206.18 & 9.05 & 1.74 & 0.13 & 0.51 & 6.65 \\
& 372.02 & 12.09 & 3.06 & 0.53 & 1.06 & 7.43 \\
80PBD & 41.57 & 6.52 & 0.36 & 0.04 & 0.19 & 5.92 \\
& 206.18 & 9.52 & 1.71 & 0.17 & 1.07 & 7.1 \\
100PBD & 372.02 & 12.39 & 3.06 & 0.55 & 0.18 & 7.71 \\
& 41.57 & 6.67 & 0.35 & 0.05 & 0.54 & 6.09 \\
& 206.18 & 9.87 & 1.7 & 0.21 & 1.09 & 7.41 \\
& 372.02 & 12.57 & 3.04 & 0.58 & 0.2 & 7.86 \\
\end{tabular}

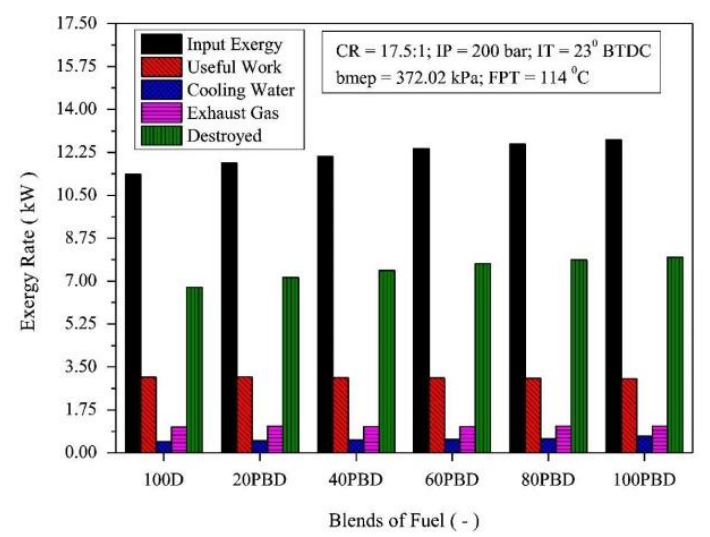

Figure 9. Exergy rates of compression ignition engine for various fuels at $372.02 \mathrm{kPa}$ bmep

Exergetic efficiency can be found as the ratio of the exergy rate of useful shaft work to the input fuel exergy rate. The exergetic efficiency for different blends of fuel with engine bmep $_{s}$ is shown in Figure 10a. The efficiency indicates the same trend as the energetic efficiency curves, however relatively lower values under the same engine bmeps conditions. At $372.02 \mathrm{kPa}$ bmep, the exergetic efficiency is nearly $6.65 \%, 6.33 \%, 6.50 \%, 6.66 \%$, $6.85 \%$ and $7.14 \%$ lower than energetic efficiency of $100 \mathrm{D}, 20 \mathrm{PBD}, 40 \mathrm{PBD}, 60 \mathrm{PBD}, 80 \mathrm{PBD}$, and $100 \mathrm{PBD}$, respectively. This is due to the inlet fuel energy is 6.75 to $7.69 \%$ lower than inlet fuel exergy, which causes the difference between two efficiencies at same test fuels and operating conditions, due to the influences of chemical exergy factors of the engine. At $372.02 \mathrm{kPa}$ engine bmep, the exergetic efficiencies for all blends of fuel lie between $23.7 \%$ and $27.2 \%$. The exergetic efficiency of the engine considering all blends of fuel from higher to lower are generally as follows: $100 \mathrm{D}>20 \mathrm{PBD}>40 \mathrm{PBD}>60 \mathrm{PBD}>80 \mathrm{PBD}>20 \mathrm{PBD}$. This is due to the increasing percentage fractions biodiesel in blend ratio caused to gradually increase kinematic viscosity which prevents a formation of better air-fuel mixture. This tends to deteriorate the combustion efficiency and decrease exergetic efficiency.

There is an opposite trend between exergy destruction and exergetic efficiency for blends of fuel (Figure 10b). It is seen that blends of has higher exergy destruction at varying bmeps compared to diesel fuel(100D), When the amount of exergy destruction increases the exergetic efficiency of blends fuel decreases as expected. The exergy destruction of various blends of fuel was obtaind maximum at lower bmeps $(41.57 \mathrm{kPa})$. So, they are inversely proportional with increasing engine bmeps.

Entropy generation rate defines the performance of the engines. It is due to heat transfer during the thermal engine cycle. It also plays a key role in the thermodynamics of irreversible processes. The entropy generation increases with the engine bmeps increasing for all blends of fuel (shown in Figure 10c). It is directly proportional 
to the bmeps. The entropy generation rates of the engine considering all the blends of fuel from higher to lower are mentioned as: 100PBD > 80PBD > 60PBD > 40PB > 20PBD > 100D. At $372.02 \mathrm{kPa}$ engine bmep, the entropy generation for all blends lies between $0.0225 \mathrm{~kW} / \mathrm{K}$ and $0.0265 \mathrm{~kW} / \mathrm{K}$.

Sustainability index (SI) is the key to determine the sustainable option for the optimization of the compression ignition engine. The SI is related with exergy efficiency to assess the engine effectively. The SI results are directly proportional to the engine loads or bmeps. The variation of sustainability index analysis of blends of fuel with engine bmeps is displayed in Figure 11. It is maximum at $372.02 \mathrm{kPa}$ and minimum at $41.57 \mathrm{kPa}$ for varied the blends of fuel. The COME (biodiesel) fuel are less sustainable than the diesel fuel, due to the relatively a high consumptions of biodiesel in the engine for every bmeps leading a lower exergetic efficiency and sustainability index. Increasing the percentage fractions of a biodiesel in the blend ratios caused to drop the SI. Hence, the sustainability index of the test fuels are as follows: 100D > PBD20 > PBD40 > PBD60 > PBD80 > PBD100 at every engine bmeps. As a result, the engine is better sustainable if the low blends of fuel are run in the engine compared to high levels of blended fuel diesel fuel. At $372.02 \mathrm{kPa}$ bmep, the sustainable index for 100D, 20PBD, 40PBD, 60PBD, 80PBD and 100PBD of fuels are 1.37, 1.35, 1.34, 1.32, 1.31 and 1.31, respectively.

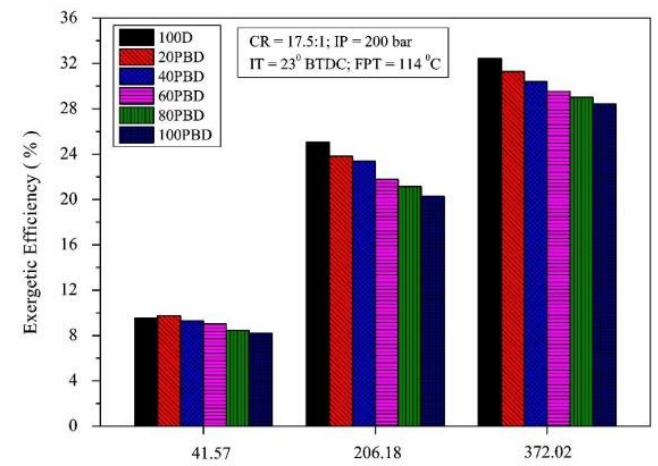

(a)

Engine bmep ( $\mathrm{kPa}$ )

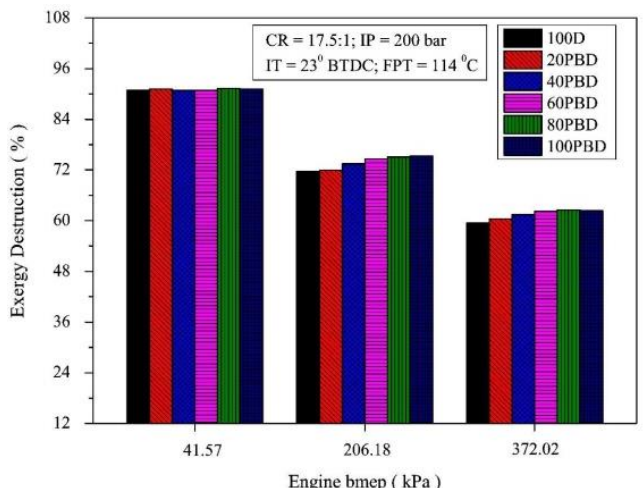

(b)

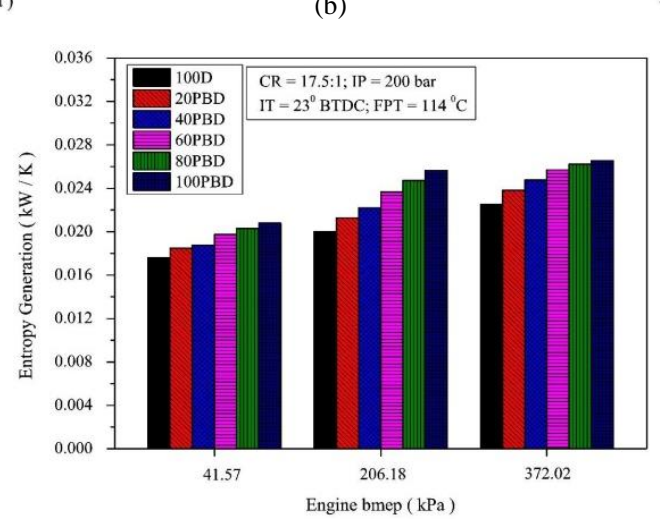

(c)

Figure 10. Exergy parameters of compression ignition engine for blends fuel with engine bmeps: (a) Exergetic efficiency, (b) Exergy destruction, and (c) Entropy generation

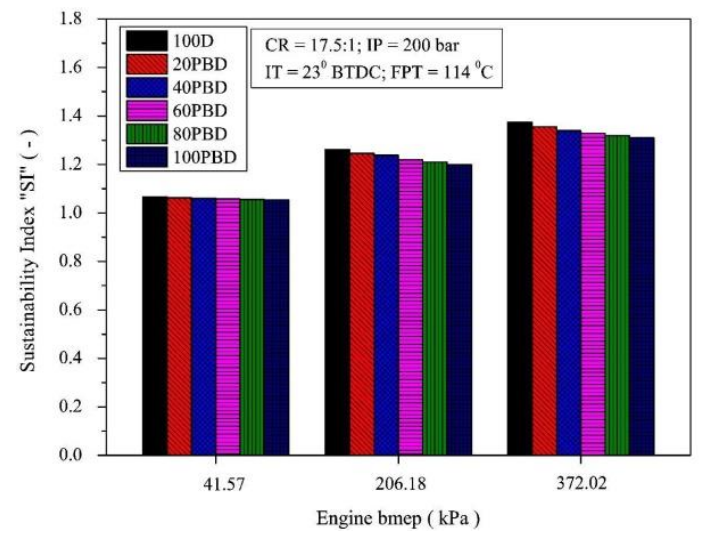

Figure 11. Sustainability index of engine for blends of fuels with engine bmeps 


\subsubsection{Exergy Cost Analysis}

In the present study, diesel fuel and five different preheated blends of fuels (20PBD, 40PBD, 60PBD, 80PBD and 100PBD) were used in a compression ignition engine. All test fuels were run at constant $372.02 \mathrm{kPa}$ engine bmep and $1500 \mathrm{rpm}$ engine speed. When the engine was run by blends of fuel a product stream of the engine was generated effective power and destruction of exergy due to irreversibility from inlet fuel exergy rate. When the engine was run by the $100 \mathrm{D}$ at $372.02 \mathrm{kPa}$ bmep, the amount fuel input exergy was entered the engine at a rate of $40.65 \mathrm{MJ} / \mathrm{hr}$. with a unit cost, cfuel $=0.027 \$ / \mathrm{MJ}$. And the fuel input exergy rate converted to the effective useful exergy rate was found to be $11.108 \mathrm{MJ} / \mathrm{hr}$., while the total exergy rate of destroyed within the engine was $27.469 \mathrm{MJ} / \mathrm{hr}$., respectively. When the engine was run by the 20PBD, the amount input fuel exergy rate was obtained with $42.510 \mathrm{MJ} / \mathrm{hr}$. with a unit cost, cfuel $=0.042 \$ / \mathrm{MJ}$. And the input fuel exergy rate converted to the effective useful exergy rate was found to be $11.144 \mathrm{MJ} / \mathrm{hr}$., while the total exergy rate of destroyed within the engine was $29.202 \mathrm{MJ} / \mathrm{hr}$., respectively. When the percentage fractions of biodiesel in blend ratio increases, the amount of input fuel exergy rate entered into the engine was seen increased with a decreased of the effective useful exergy rates due to an increase of exergy rate of destruction. Hence, when the engine was run by the 100PBD, the amount fuel input exergy rate was increased with $45.929 \mathrm{MJ} / \mathrm{hr}$. with a unit cost, cfuel $=0.104$ $\$ / M J$. And the input exergy fuel rate converted to the effective useful exergy rate was found decreased with $10.887 \mathrm{MJ} / \mathrm{hr}$., whereas the total exergy rate of destroyed within the engine was increased to $32.815 \mathrm{MJ} / \mathrm{hr}$., respectively. In the present study, it was used the same engine for all test fuels, hence the engine capital cost was $0.03126 \$ / \mathrm{hr}$., and operating and maintenance cost of the system (engine) was $0.02726 \$ / \mathrm{hr}$. (Table 5). The cost per exergy unit of the engine such as the cost per input fuel exergy unit (cfuel), the cost per exergy unit of the generated power output (csw) and the cost per exergy unit of destruction (cdestr) for blends of fuel is tabulated Table 5.

Table 5. The fuel cost rates associated with blends of fuel, and cost per product exergy unit

\begin{tabular}{cccc}
\hline Fuel & $C_{\text {fuel }}(\$ / \mathrm{MJ})$ & $C_{s w}(\$ / \mathrm{MJ})$ & $C_{\text {destr }}(\$ / \mathrm{MJ})$ \\
\hline 100D & 0.027 & 0.171 & 0.111 \\
20PBD & 0.042 & 0.272 & 0.166 \\
40PBD & 0.056 & 0.382 & 0.221 \\
60PBD & 0.072 & 0.499 & 0.278 \\
80PBD & 0.088 & 0.625 & 0.339 \\
100PBD & 0.104 & 0.754 & 0.397 \\
\hline
\end{tabular}

The results are shown in Figure 12(a), it was noticeable that there was cost rate associated with energy from sources of different blends of fuel, the energy must be paid for. It was comprehensible that the cost rate of 4.43 $\$ / \mathrm{hr}$. associated with 100PBD was the highest among all energy sources due to a recent high biodiesel oil price. The cost rate associated with diesel fuel (100D) was $1.04 \$ / \mathrm{hr}$., approximately four times smaller than that associated with 100PBD. However, the cost rate associated with 40PBD was two times higher than diesel fuel (100D) and two times smaller than neat preheated biodiesel (100PBD). The Cost rate is increased even more dramatically for increasing percentage fractions of biodiesel in blend ratios. At the moment, among the five types of blends of fuel, up to 40PBD blends of fuel was found the best fuels to provide the lowest cost rate compared to high levels of blended fuel. But, in case of cheaper mass production carried out, at least compete with diesel fuel price; using 100PBD blend of fuel would become economic due to sufficiently enough supply of biodiesel to the world market to run in a diesel engine as a diesel fuel which leads significant reduction of price of biodiesel oil. The capital investment on the various test fuels were the same (Table 2). It was obvious that the cost rate on 100PBD was the highest among the other test fuels. This is due to a high production cost of one Liter of biodiesel comparing with one Liter of mineral diesel fuel because of a small scale production was carried out for the existing demand. Hence in today market, the cost of one Liter neat biodiesel (COME) was obtained 3.52 \$ which is about three times higher than the price of one Liter mineral diesel fuel (100D) of 1.029 \$ (Table 2). However, the biodiesel oil offered extra benefits for developing countries economy, creating new jobs, reduced toxic exhaust emission and meet emission norms. In view of this, today in many developed countries are engaged in a mass scale production of biodiesel from vegetable oil and animal fats to substitute diesel fuel partly or full and satisfied a high energy requirements of fast industrialization. This provides a great opportunity in a long term operation and the price of biodiesel may reduce significantly even below the current price of diesel fuel, thus at this circumstance the cost rate per useful exergy unit of a high levels blend (up to100PBD) run a diesel engine may be lowest instead of diesel fuel (100D). 


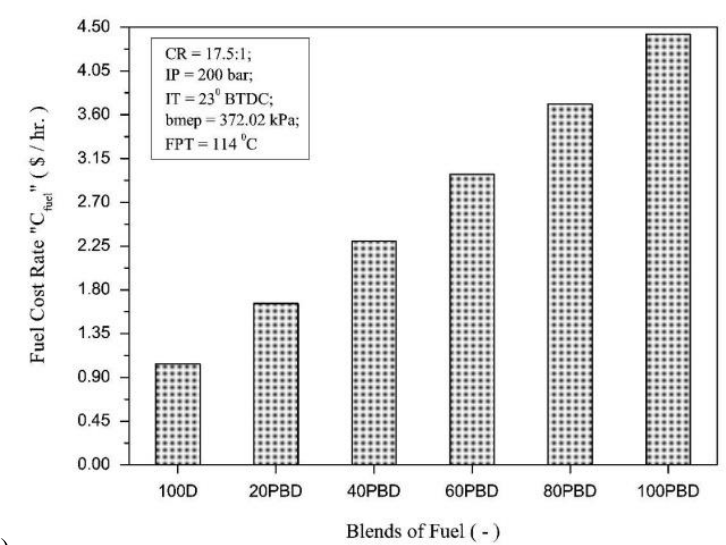

(a)

Figure 12. Cost analysis for

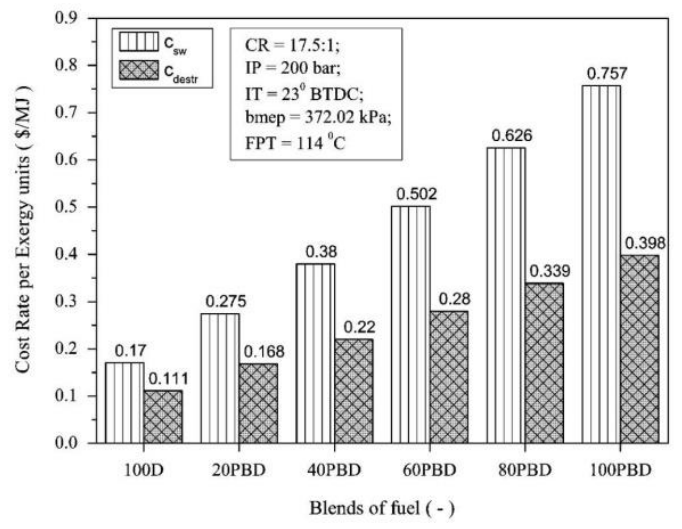

(b)

Cost per useful exergy, and (c) Cost per destruction exergy

Figure 12(a-b) shows the results of cost per exergy unit obtained from the analyses of the engine. Among the different blends of fuel, the cost per useful power exergy of 100PBD was highest, with the price of 0.75759 \$/MJ (Figure 12(a)). This was due to the very high biodiesel oil price in the market. While, the neat diesel fuel (100D) was lowest and found to be 0.1708 \$MJ. Increasing the percentage fractions of biodiesel in blend mixture ratios, the cost per generated useful power exergy was shown increasing, due to the price increments of blends of fuel with increasing fractions of biodiesel in mixture ratios. Similarly, from the cost per destruction exergy of 100PBD was higher, with price of $0.39869 \$ / \mathrm{MJ}$, whereas for the cost per destruction exergy due irreversibility of 100D was found lowest with 0.11117 \$MJ (Figure 12b). The results of full economic analysis (fuel cost, and useful exergy and exergy destruction), it was found that the most economical blends were (20PBD-60PBD), and the costly blends were (80PBD-100PBD), respectively compared to diesel fuel (100D). It is concluded that the best thermodynamic condition of the engine occurred when the engine was fueled with pure diesel fuel, and the most economical condition occurred with the 20PBD and 40PBD blends.

\section{Conclusion}

In the present investigation, thermodynamic, sustainability and thermo-economic analyses of a compression ignition engine was executed. To this objective, the castor oil methyl ester was preheated and blends with a diesel fuel to optimize the performance of the fuel usage as a diesel fuel at any levels of blend ratios in the compression ignition engine without malfunction. In this study, the diesel fuel (100D) and five blends of fuel from 20 to $100 \%$ by volume (20PBD, 40PBD, 60PBD, 80PBD and 100PBD) were used in the engine at varying engine bmeps operating conditions. Based on the experimental investigations, the following conclusions are drawn:

- The increase fuel preheating temperature of COME at $114^{\circ} \mathrm{C}$, the kinematic viscosity and density decreases to the ranges of biodiesel standards and close to diesel fuel. This results an improved BSFC and BTHE, however beyond $114 \mathrm{C}$ the results getting worsen.

- The percentage fraction of biodiesel is inversely proportional to both LHVs and BSFC. The effect of preheating and low blend ratios COME with diesel fuel improves the LHVs of the fuels and BSFC of engine.

- Preheating and high levels of blend ratios provided maximum input fuel energy and exergy rate compared to diesel fuel (100D). Because, input energy and exergy rate is directly proportional to the mass flow rate of fuel and LHVs.

- Input fuel exergy rate is higher than fuel energy rate for all blends of fuel, due to chemical exergy factors of each fuel.

- Low levels of blend of fuels have a better energetic and exergetic efficiency at every bmeps operation. At $372.02 \mathrm{kPa}$ bmep, the energetic and exergetic efficiency of 20PBD fuel was maximum with $27.98 \%$ and $26.21 \%$, and close to diesel fuel $(29.12 \%$ and $27.18 \%)$, respectively. It means that, the percentage fractions of biodiesel are inversely proportional to useful exergy.

- The entropy generation of blends of fuel increased with increasing percentage fractions of biodiesel. It is 
also increased with increasing engine bmeps.

- At low engine bmep, all blends of fuel have a similar sustainability index with diesel fuel, however, increasing the bmeps, the sustainability index of diesel fuel was seen better.

- All blends of fuel offered quite higher economic cost with respect to diesel fuel. This is due to fuel price per liter of COME is quite higher than diesel fuel.

- The results of full economic analysis (fuel cost, fuel consumption and generating useful exergy and exergy destruction) showed that only up to $60 \%$ biodiesel-diesel blends of fuel (20PBD-60PBD) were more affordable compared to diesel fuel.

\section{Acknowledgments}

The author appreciatively acknowledges that the present research is supported by Ministry of Defence, Federal Democratic Republic of Ethiopia. The support was assisted under in the $\mathrm{PhD}$ research study.

\section{References}

Aksoy, F., Baydir, S. A., \& Bayrakçeken, H. (2009). An investigation on the effect in the viscosity of canola and corn oil biodiesels at a temperature range of 0 to 100 C. Energy Sources, Part A: Recovery, Utilization, and Environmental Effects, 32(2), 157-164. https://doi.org/10.1080/15567030802463869

Altın, R., Cetinkaya, S., \& Yücesu, H. S. (2001). The potential of using vegetable oil fuels as fuel for diesel engines. Energy conversion and management, 42(5), https://doi.org/10.1016/S0196-8904(00)00080-7

Balat, M. (2006). Fuel characteristics and the use of biodiesel as a transportation fuel. Energy Sources, Part A, 28(9), 855-864. https://doi.org/10.1080/009083190951474

Caliskan, H., \& Mori, K. (2017). Thermodynamic, environmental and economic effects of diesel and biodiesel fuels on exhaust emissions and nano-particles of a diesel engine. Transportation Research Part D: Transport and Environment, 56, 203-221. https://doi.org/10.1016/j.trd.2017.08.009

Caliskan, H., Tat, M. E., Hepbasli, A., \& Van Gerpen, J. H. (2010). Exergy analysis of engines fuelled with biodiesel from high oleic soybeans based on experimental values. International Journal of Exergy, 7(1), 20-36. https://doi.org/10.1504/IJEX.2010.029612

Cengel, Y. A., \& Boles, M. A. (2007). Thermodynamics: An Engineering Approach (6th ed., SI Units). The McGraw-Hill Companies, Inc., New York.

Da Costa, Y. J. R., de Lima, A. G. B., Bezerra Filho, C. R., \& de Araujo Lima, L. (2012). Energetic and exergetic analyses of a dual-fuel diesel engine. Renewable and Sustainable Energy Reviews, 16(7), 4651-4660. https://doi.org/10.1016/j.rser.2012.04.013.

Debnath, B. K., Sahoo, N., \& Saha, U. K. (2013). Thermodynamic analysis of a variable compression ratio diesel engine running with palm oil methyl ester. Energy Conversion and Management, 65, 147-154. https://doi.org/10.1016/j.enconman.2012.07.016

Karabektas, M., Ergen, G., \& Hosoz, M. (2008). The effects of preheated cottonseed oil methyl ester on the performance and exhaust emissions of a diesel engine. Applied Thermal Engineering, 28(17-18), 2136-2143. https://doi.org/10.1016/j.applthermaleng.2007.12.016

Kegl, B., Kegl, M., \& Pehan, S. (2013). Green diesel engines. Biodiesel Usage in Diesel EnginesSpringer-Verlag, London.

Khan, M. Y., Khan, S. Y., \& Ahmad, N. (2006, December). Performance characteristics of compression ignition engine when operated on preheated Neem oil. In Proceeding of International Conference on Advances in Mechanical Engineering, Punjab (pp. 1-3).

Knothe, G. (2006). Analyzing biodiesel: standards and other methods. Journal of the American Oil Chemists' Society, 83(10), 823-833. https://doi.org/10.1007/s11746-006-5033-y

Lin, C. Y., Chen, L. W., \& Wang, L. T. (2006). Correlation of black smoke and nitrogen oxides emissions through field testing of in-use diesel vehicles. Environmental Monitoring and Assessment, 116(1-3), 291-305. https://doi.org/10.1007/s10661-006-7402-2

López, I., Quintana, C. E., Ruiz, J. J., Cruz-Peragón, F., \& Dorado, M. P. (2014). Effect of the use of olivepomace oil biodiesel/diesel fuel blends in a compression ignition engine: Preliminary exergy analysis. Energy conversion and Management, 85, 227-233. https://doi.org/10.1016/j.enconman.2014.05.084 
Meisami, F., \& Ajam, H. (2015). Energy, exergy and economic analysis of a Diesel engine fueled with castor oil biodiesel. International Journal of Engine Research, 16(5), 691-702. https://doi.org/10.1177/1468087415576609

Meisami, F., Ajam, H., \& Tabasizadeh, M. (2018). Thermo-economic analysis of diesel engine fueled with blended levels of waste cooking oil biodiesel in diesel fuel. Biofuels, 9(4), 503-512. https://doi.org/10.1080/17597269.2017.1284475

Misra, R. D., Jena, J., \& Murthy, M. S. (2013). Energy and exergy analyses of a CI engine fuelled with palm biodiesel based on experimental data. International Journal of Exergy, 13(1), 124-139. https://doi.org/10.1504/IJEX.2013.055784

Mohan, B., Yang, W., Raman, V., Sivasankaralingam, V., \& Chou, S. K. (2014). Optimization of biodiesel fueled engine to meet emission standards through varying nozzle opening pressure and static injection timing. Applied energy, 130, 450-457. https://doi.org/10.1016/j.apenergy.2014.02.033

Moon, G., Lee, Y., Choi, K., \& Jeong, D. (2010). Emission characteristics of diesel, gas to liquid, and biodiesel-blended fuels in a diesel engine for passenger cars. Fuel, 89(12), 3840-3846. https://doi.org/10.1016/j.fuel.2010.07.009

Naik, M., Meher, L. C., Naik, S. N., \& Das, L. M. (2008). Production of biodiesel from high free fatty acid Karanja (Pongamia pinnata) oil. Biomass and Bioenergy, 32(4), 354-357. https://doi.org/10.1016/j.biombioe.2007.10.006

Narayan, C. M. (2002). Vegetable oil as engine fuels-prospect and retrospect. Proceedings on recent trends in automotive fuels, Nagpur, India, 1, 22-26.

Ozsezen, A. N., \& Canakci, M. (2011). Determination of performance and combustion characteristics of a diesel engine fueled with canola and waste palm oil methyl esters. Energy Conversion and Management, 52(1), 108-116. https://doi.org/10.1016/j.enconman.2010.06.049

Rambabu, V., Prasad, V. J. J., \& Subramanyam, T. (2013). Evaluation of performance and emissions of a VCR DI diesel engine fuelled with preheated CsME. Global Journal of Research in Engineering, 12(7-A). Retrieved from https://www.engineeringresearch.org/index.php/GJRE/article/view/687

Sorathia, H. S., \& Yadav, H. J. (2012). Energy analyses to a ci-engine using diesel and bio-gas dual fuel-a review study. World, 1(5).

Tat, M. E. (2011). Cetane number effect on the energetic and exergetic efficiency of a diesel engine fuelled with biodiesel. Fuel Processing Technology, 92(7), 1311-1321. https://doi.org/10.1016/j.fuproc.2011.02.006

Venkanna, B. K., \& Venkataramana Reddy, C. (2013). An experimental investigation on the performance, emission and combustion characteristics of preheated calophyllum inophyllum linn oil (honne oil) fed DI diesel engine. International Journal of Energy Technology and Policy, 9(1), 1-14. https://doi.org/10.1504/IJETP.2013.055813

Yusuf, N. N. A. N., Kamarudin, S. K., \& Yaakub, Z. (2011). Overview on the current trends in biodiesel production. Energy Conversion and Management, 52(7), 2741-2751. https://doi.org/10.1016/j.enconman.2010.12.004

\section{Copyrights}

Copyright for this article is retained by the author(s), with first publication rights granted to the journal.

This is an open-access article distributed under the terms and conditions of the Creative Commons Attribution license (http://creativecommons.org/licenses/by/4.0/). 